\title{
Regenerative Agriculture: Beyond Sustainability
}

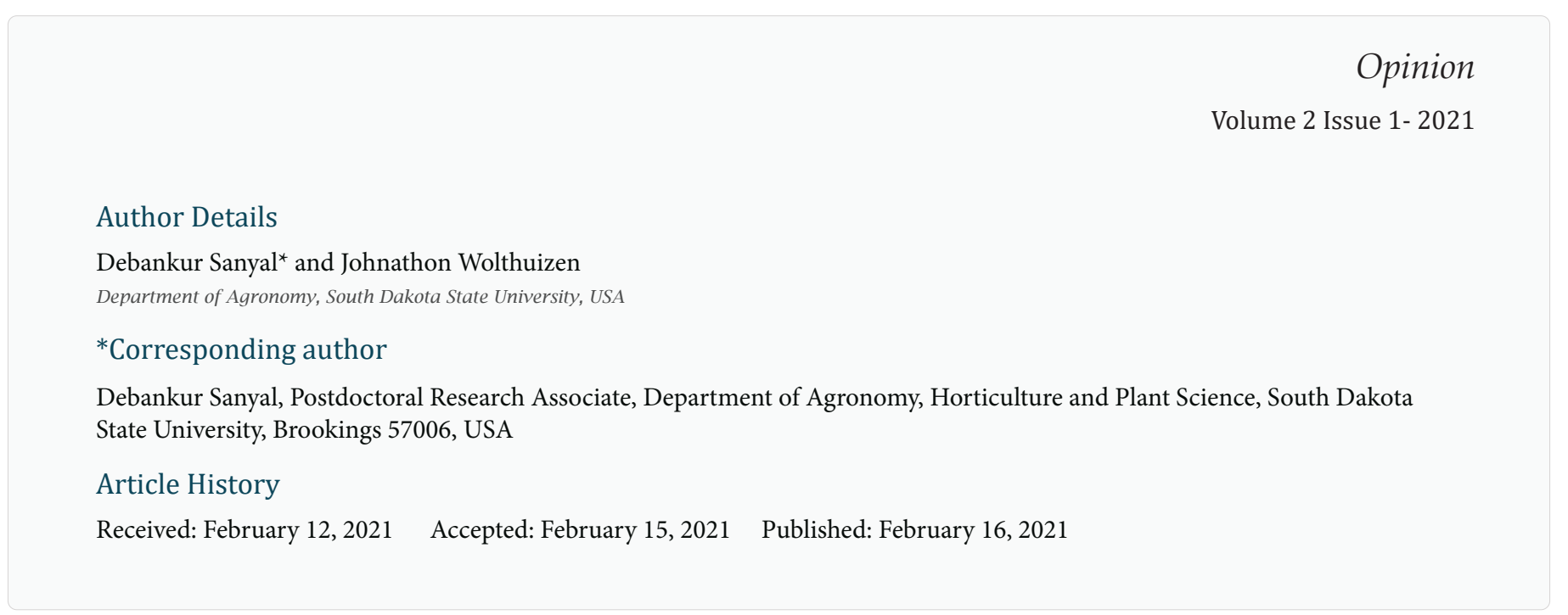

\begin{abstract}
Sustainable agriculture (SA) is a well-discussed practice to ensure resilient socio-economic status of farms while protecting our environment. While regenerative agriculture (RA) is relatively new and comprised of the same tools and techniques as SA. Recently, researchers are leaning towards the term 'regenerative' over the term 'sustainable' as they look at this approach as the next step ahead of SA. In this article, we discuss our opinion regarding the necessary switch to RA from SA.
\end{abstract}

\section{Opinion}

Sustainable agricultural (SA) practices were introduced as an integral part of our crop and animal production system to achieve a long-term goal of satisfying the human need of food, fiber, and fuel, providing economic stability to the farms and improving environmental quality for holistic strengthening of socio-economic status of the farming community [1]. After World War II, agricultural intensification and increased mechanization of farming was depleting soil fertility and productivity. This, coupled with rapid industrial growth, caused a drastic decline in environmental quality and began changing the global climate. The concept of sustainable agriculture came out as a necessary approach to combat the adverse effects of climate change on agriculture and as a way to bolster food security for the increasing global population, without harming the environment [2]. Researchers all around the world were presenting reports that conventional ways of farming would destroy all major natural resources like land, water and air and global policymakers collaborated with scientists and leaders in devising plans for sustainable development goals (SDG) [3]. Priority was given to soil and crop management techniques to maintain soil functions, in the agroecosystems, that can provide enough food for the increasing population while substantially reducing negative impacts of farming such as groundwater contamination and anthropogenic emissions. The idea was efficient utilization of natural resources while increasing production of food, fuel and fiber, maintaining an improved level of natural resources and environment quality.
Regenerative agriculture (RA) is a relatively new term that does not have a rigid definition rather it is a farming concept that is built upon the idea that 'no-size-fits-all' and is a system-specific, holistic approach that is required to achieve SDG [4]. RA practices or techniques are similar to that of SA, but the tools and techniques are fine tuned for specific agroecosystem and is soil-based rather than seed based [4,5]. The major emphasis is given to improving nutrient cycling through soil by improving soil organic matter (SOM) status and creating a positive carbon $(\mathrm{C}$ ) budget using soil as a $\mathrm{C}$ sink in the terrestrial $\mathrm{C}$ pool assuring enhanced soil functions and minimal exploitation of natural resources. The term 'regenerative' is different from the term 'sustainable' in its essence. While SA is aimed at maintaining a desired or improved level of ecosystem functions, RA aims at regenerating, renewing and further improving the soil functions and ecosystem capabilities in an ever-improving process. Therefore, scientists in recent years prefer the term 'regenerative' over the term sustainable. We should not seek to simply maintain something that is degraded when we have the ability to improve it. Much in the same way if we were sick and our doctor claimed they could make it so you did not get sicker, you just would not get better. Our agricultural lands are sick, but we can heal them with the correct practices.

Regenerative Agriculture is primarily based on improving soil functionality, soil quality or soil health and use RA as a tool to impart climate and economic resiliency into the agroecosystems. In the current scenarios of climate and environmental issues, the health of soil, crops, 
livestock, human and environment are tied together, specifically in the COVID-19 era, the goal should be obtaining sustainable yield though enhancement of soil health and resiliency, with minimal dependance on chemicals and other artificial substances. It is necessary to regenerate our agroecosystems as with increasing demands of food, fuel, and fiber, a short-term sustainability plan might not be enough to support the demand in the near future, and only a regenerating and renewable system can promise food security on a long-term basis.

Regenerative agriculture includes a package of practices, specifically designed for strengthening soil resiliency on a farm or ecoregion, therefore participation of the farming communities, the farmers, ranchers and other stakeholders, is indispensable. The techniques to study the impacts of RA are similar to that of SA or soil health assessments, but cultural assessments are generally missing or limited in soil quality assessments because of complexity and lack of empirical measurements [5,6]. Therefore, combining local (farmers) and technical (researchers) indicators for assessing the influence of RA is necessary to understand the impacts of RA; however, impact assessment is limited due to contrasting results. Devising new tools that can combine both farmers' and researchers' observations to address the impacts of RA on the agroecosystems, such as visual soil assessment (VSA) [7], is probably the area where a lot of scientific exploration is required. VSA combines farmer-assessment indicators such as erosion, water regulation, crop performance, earthworm counts [8] whereas technical indicators include aggregate stability, nutrient concentrations, microbial activities [7]. Designing more assessment tools to popularize the idea of positive impacts of RA is a need of this century.

Sustainable agriculture in its essence seeks to sustain a resource that has already been damaged by industrial agriculture and intensive agricultural practices, but a truly regenerative system seeks to undo the damage done to that natural resource, especially soil. This should be done by improving the efficiency of our production systems through optimized utilization of natural resources. Lal [4], the 2020 World Food Prize winner, claimed that we produce enough food to feed 10 billion people, but we waste $30 \%$ of it. The cycle of productionwaste-pollution-more production should be broken, while the aim of RA should be at producing 'more from less'. We should prepare for the 21st Century Green Revolution following the strategies of RA and we should not stop improving, regenerating and renewing our agroecosystems when we reach the sustainability in the short term, instead we should practice RA to achieve long term sustainable goals. In this way, we can advance from a sustained environment to a regenerating environment.

\section{References}

1. Stansbury DL (1986) National Agricultural Research, Extension, and Teaching Act of 1977. New Dir Agric Agric Res 1-63.

2. Pretty J (2008) Agricultural sustainability: Concepts, principles and evidence. Philos Trans R Soc B Biol Sci 363(1491): 447-465.

3. United Nations (2016) Transforming Our World: The 2030 Agenda For Sustainable Development.

4. Lal R (2020) Regenerative agriculture for food and climate. J Soil Water Conserv 75(5): 123A-124A.

5. Schreefel L, RPO Schulte, IJM de Boer, AP Schrijver, HHE van Zanten (2020) Regenerative agriculture - the soil is the base. Glob. Food Sec 26(August): 100404.

6. Stavi I, G Bel, E Zaady (2016) Soil functions and ecosystem services in conventional, conservation, and integrated agricultural systems. A review Agron Sustain Dev 36(2).

7. Luján Soto R, M Cuéllar Padilla, J de Vente (2020) Participatory selection of soil quality indicators for monitoring the impacts of regenerative agriculture on ecosystem services. Ecosyst Serv 45: 101157.

8. Sanyal D, J Wolthuizen, A Bly (2020) How's Life in the Soil? Ask (Count) the Earthworms. 